\title{
Tradeoffs to Thermal Acclimation: Energetics and Reproduction of a Reef Coral with Heat Tolerant Symbiodinium Type-D
}

\author{
Alison M. Jones ${ }^{1}$ and Ray Berkelmans ${ }^{2}$ \\ ${ }^{1}$ Central Queensland University, Bruce Highway, Rockhampton, QLD 4702, Australia \\ ${ }^{2}$ Australian Institute of Marine Science, PMB 3, Townsville Mail Centre, Townsville, QLD 4810, Australia
}

Correspondence should be addressed to Alison M. Jones, a.jones@cqu.edu.au

Received 9 November 2010; Revised 17 February 2011; Accepted 7 March 2011

Academic Editor: Horst Felbeck

Copyright ( 2011 A. M. Jones and R. Berkelmans. This is an open access article distributed under the Creative Commons Attribution License, which permits unrestricted use, distribution, and reproduction in any medium, provided the original work is properly cited.

\begin{abstract}
The photo-physiological characteristics of thermo-tolerant Symbiodinium types have been postulated to have negative effects on the energetics of the reef corals by reducing fitness. To investigate this, two key and inextricably coupled indicators of fitness, lipids and reproduction, were monitored in colonies of the broadcast-spawning coral Acropora millepora over a two-year period that included a natural bleaching event. In the absence of bleaching ITS1-type clade D predominant colonies had 26\% lower stored lipids compared to C2 colonies. At spawning time, this correlated with $28 \%$ smaller eggs in type-D colonies. This energetic disparity is expected to have reduced larval duration and settlement-competency periods in type-D compared to type-C2 colonies. More importantly, irrespective of the effect of genotype, the fitness of all corals was adversely affected by the stress of the bleaching event which reduced prespawning lipids by $60 \%$ and halved the number of eggs compared to the previous year. Our results extend work that has shown that direct temperature stress and symbiont change are likely to work in concert on corals by demonstrating that the lipids and reproduction of the reef building corals on tropical reefs are likely to be impaired by these processes as our climate warms.
\end{abstract}

\section{Introduction}

Reef-building corals are vulnerable to climate change as they live in a narrow thermal range and are extremely sensitive to variations. An increase of only $1-2^{\circ} \mathrm{C}$ above the coral's normal summer maximum, in combination with light, can cause expulsion of the endosymbiotic algae (zooxanthellae) that live within their tissues, resulting in coral bleaching [1]. Such extremes are expected to occur regularly on reefs within the next century meaning that corals must adapt or acclimatize at a rate of $0.2^{\circ} \mathrm{C}$ every decade if they are to keep pace with even the lowest predicted temperature rise of $2^{\circ} \mathrm{C}$ by 2100 [2]. One way in which corals can increase their heat tolerance is by changing their endo-symbiont community to more thermally tolerant types like Symbiodinium type D [3]. Hosting a viable population of heat tolerant symbionts may give corals a better chance of surviving repeated bleaching events [4]. A recent study utilizing novel molecular methods has revealed previously undetectable levels $(<5-10 \%)$ of thermally tolerant symbionts types in four species of reef corals [5], raising the possibility that many species may be able to acclimatize to climate change in this way $[6,7]$. So far, symbiont changes have been transitory $[8,9]$, and it remains to be seen whether they will become permanent as sea temperatures increase and the return time between anomalously warm summers decreases. The phenomenon of symbiont change raises the question: what effects will symbiont change have on holobiont (coral + endosymbionts) energetics and what will this mean to the capacity for coral reefs to recover following disturbance?

The overall energy budget of reef-building corals is influenced by the genotype of their algal endosymbionts. Shallow water reef corals rely in large part on energy derived from symbiont photosynthesis [10]. The symbionts use photochemical energy to fix carbon to produce low molecular weight carbon compounds such as glycerol and triglycerides, a large proportion of which are then translocated to their host as lipids [11]. The lipids are used as an energy store 
for processes such as tissue growth [12], skeletal growth [13], and reproduction [14]. Genotypic differences have been found in the translocation rates of photosynthetically fixed ${ }^{14} \mathrm{C}$ to the tissues of juvenile A. millepora [15]. In laboratory studies of isolated coral zooxanthellae, the genetic identity of the symbionts influenced the amounts of ${ }^{14} \mathrm{C}$ fixed and released by the host [16]. These and other studies suggest that symbiont genotype may affect host growth rates in juvenile $[17,18]$ and adult corals [19]. Since skeletal growth is affected by symbiont type it follows that host energetics and fecundity may also vary with symbiont type. However, until now, this link and the magnitude of any such dependence have not been demonstrated.

There is strong evidence from higher plants that there is a link between energetics and thermal tolerance, a feature which is also likely to exist in marine autotrophs like Symbiodinium because of shared photosystem mechanisms. For example, analysis of chloroplast thylakoid membranes revealed that the critical threshold temperature separating thermally tolerant from sensitive species of Symbiodinium is determined by the saturation of the lipids [20]. Just as in plants, increased saturation state of the thylakoid membranes influences the temperature at which the photosystems become unstable [21]. The most significant consequence of increased polysaturation of the thylakoid membranes for marine autotrophs is that in plants this trait has been shown to reduce the amount of energy available for growth [21]. If Symbiodinium utilise similar mechanisms for heat tolerance then it follows that there may be downstream effects on coral energetics. A productivity cost as a result of thermal tolerance may in fact have more than one source: first, reduced photosynthetic activity due to increased polyunsaturation of the thylakoid membranes and second, the now limited energetic resources are diverted to cope with stress [22]. This suggests that although increased thermal tolerance represents a survival benefit, it might not represent an energetic benefit because it may reduce the physical fitness of the organism, or in the case of corals, the holobiont.

Reef-building, or scleractinian, corals form the physical structure of tropical reefs, providing habitat and food for a variety of other marine organisms. Following disturbance, reef regeneration is provisional upon the recruitment and regrowth of individuals of the key structural species [23]. Processes that are energy costly such as thermal stress [24], low salinity [25], and spawning [26] can increase the risk of disease and mortality and impair energetic processes following environmental disturbance [9, 27-29]. In particular, in corals, key regeneration processes like reproduction [29] and larval dispersal and settlement [30], are dependent on the availability of stored lipids. If lipid stores are depleted by metabolic processes involved in recovery from stress then less lipids are available for egg production [31]. The situation is potentially compounded if the coral recovers from a disturbance with a more thermally tolerant, but less autotrophically efficient symbiont type. In this case there could be a compounding effect of symbiont identity and the direct effects of the stress on host energetics and reproduction, potentially affecting the capacity of a reef to regenerate by recruitment.
This study quantifies stored lipids and reproduction; two factors which are critical for coral community regeneration following mass bleaching. A millepora was chosen for the study because it is a common reef builder on leeward shores of the islands in the Keppel region of the southern Great Barrier Reef [32]. Colonies on these reefs naturally host mixed or uniform communities of thermally sensitive type C2 and thermally tolerant type D Symbiodinium [3] making this an ideal location to study the downstream effect of symbiont genotype on lipid stores and reproductive output during normal conditions and stress such as bleaching. A bleaching event during the study provided an opportunity to investigate the lipids and reproduction of colonies during their recovery.

\section{Materials and Methods}

Storage lipids, egg size, and egg number from tagged, adult A. millepora colonies with known predominant symbiont genotype were measured seasonally over 24 months to investigate the links between predominant symbiont community identity, bleaching resistance, and colony fitness. The study was conducted before, during, and after a major bleaching event in February 2006 which caused significant mortality of colonies on reef flats and slopes in the Keppel region [33]. Before the bleaching event, colonies of A. millepora at this site naturally hosted Symbiodinium type C2 with the occasional occurrence of type $\mathrm{D}$, or mixtures of both $\mathrm{C} 2$ and D. Following the bleaching event, $71 \%$ of surviving colonies exhibited a shift in symbiont community from C2 to D and another potentially thermally tolerant type, $\mathrm{C} 1[8]$.

2.1. Sampling Design. The study took place at Miall Island $\left(23^{\circ} 09^{\prime} \mathrm{S} 150^{\circ} 54^{\prime} \mathrm{E}\right)$ in the Keppel Island group in the southern inshore Great Barrier Reef. In March 2005, 24 colonies of the Indo-Pacific stony coral A. millepora (Ehrenberg, 1834) of roughly the same size and at the same depth were chosen based on their predominant symbiont genotype. The Symbiodinium type in the colonies was verified just before the start of the experiment and at each sampling occasion in March and July 2005 and January, May, and August 2006 using Single Stranded Conformational Polymorphism (SSCP) analysis of the ITS1 region of algal nuclear ribosomal DNA. Samples from colonies with intense single SSCP bands were considered to host monomorphic (predominant) symbioses although the presence of other genotypes below 5$10 \%$ relative abundance could not be ruled out [34]. Samples with multiple bands matching $\mathrm{C} 2, \mathrm{D}$, and $\mathrm{C} 1$ were considered mixed symbioses. SSCP profiles were assigned to symbiont type by cloning representative samples per SSCP profile, followed by DNA sequencing as described in [19]. Twenty-four colonies with single, intense type C2 or type D SSCP bands were chosen for the study. Colonies were initially divided into two treatment groups: 12 colonies with predominantly type $\mathrm{C} 2$ symbionts and 12 with predominantly type D symbionts. Colonies were not regenotyped in November 2005, February 2006, or November 2006.

The symbiont community was relatively stable before the bleaching event except for two colonies which changed 


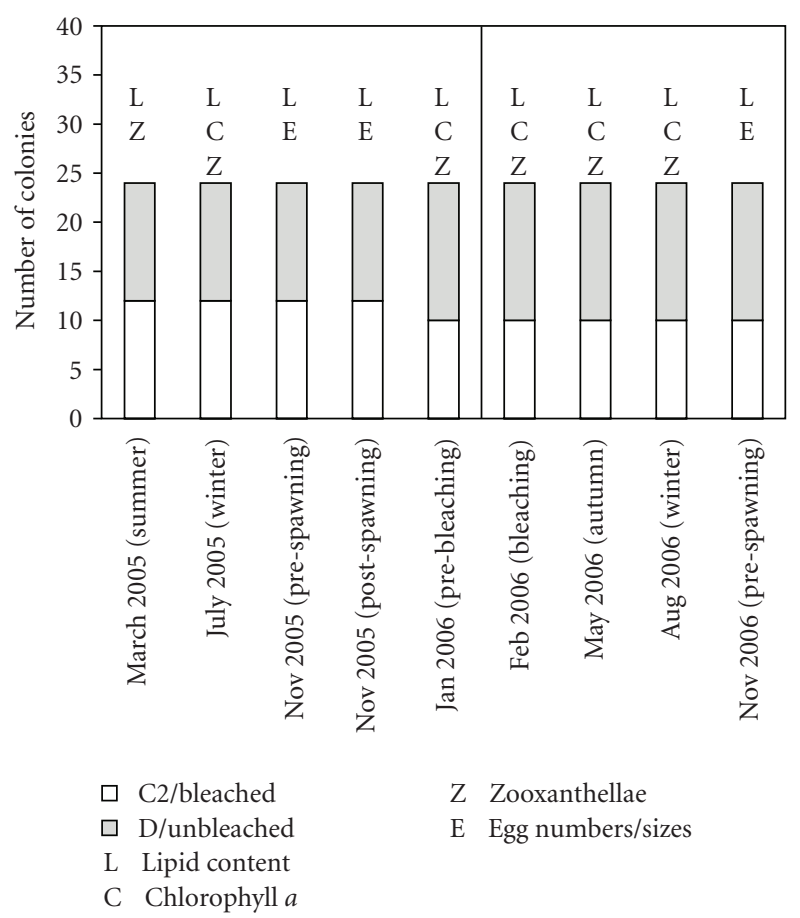

FIGURe 1: Sampling design for the study of storage lipids (L), algal chlorophyll $a$ content $(\mathrm{C})$, symbiont densities (Z), and egg sizes and numbers (E) in colonies of Acropora millepora sampled before (grey bars $=\mathrm{D}$, white bars $=\mathrm{C} 2$ ) and after (grey bars = unbleached, white bars = bleached) a bleaching event in February 2006 (shown as a thick line between January and February 2006).

from predominantly C2 symbionts in March and July 2005 to host predominantly type D symbionts in February 2006. The colonies were sampled again three months later in July 2005, then before and after spawning in November 2005, in January 2006 (at the onset of bleaching), and in February 2006 at the peak of the bleaching (Figure 1). The bleaching state of each colony was recorded throughout February 2006 by visually estimating the loss of colony colouration compared to the prebleaching state (white = bleached, normal colouration = unbleached). At this time, all 10 type $\mathrm{C} 2$ colonies had lost their normal colouration and all 14 type D colonies appeared normally coloured. After the peak of the bleaching, the same colonies were re-sampled in May 2006, August 2006, and before the annual spawning event in November 2006. The symbiont community changed dramatically following the bleaching (see Section 4.1).

At each of the three monthly sampling occasions, two branches were removed from the centre of each colony. A small piece of one branch was placed in $100 \%$ ethanol for symbiont identification and the remaining samples were snap-frozen in liquid nitrogen and subsequently stored at $-80^{\circ} \mathrm{C}$ until processed. One branch was used for the analysis of lipids and the second branch for the determination of chlorophyll a content, and symbiont densities. Algal chlorophyll $a$ content is a proxy for bleaching severity and recovery rates in corals [35].
In addition to the three monthly sampling occasions, two additional branches were removed from each tagged colony before and after spawning in November 2005 and before spawning in November 2006. A maximum diameter was recorded for each colony to determine whether colony size had any influence on reproductive output. One branch was snap-frozen in liquid nitrogen and stored at $-80^{\circ} \mathrm{C}$ for the analysis of lipids, and the second branch was stored in $10 \%$ formalin in seawater and used for the determination of reproductive output (egg number, and egg size).

2.2. Lipids. Lipid analysis was performed on dried, ground, whole coral tissue samples including zooxanthellae and skeleton. The samples were ground under liquid nitrogen [36] to produce a fine homogenous powder and placed in acetone-washed and preweighed $25 \mathrm{~mL}$ sintered glass vials. The vials containing the frozen ground samples were freezedried and weighed to four decimal places and the total dry weight of the sample (DWS) recorded. Subsamples of known weight (approx 0.1-0.5 mg) were removed for lipid analysis. Lipid measurements were standardized to coral tissue surface area using the $3 \mathrm{D}$ digital image analysis methods described in Jones et al. [37].

The total lipid content of each branch was determined using two consecutive chloroform: methanol extractions following the technique described by Folch et al. [38] and Harland et al. [39]. The organic phase was washed once with $0.88 \% \mathrm{KCl}$ and three times with methanol: water $(1: 1)$, evaporated and dried in an oven at $60^{\circ} \mathrm{C}$. The lipid content was expressed as the difference between the weight of the pan, and the weight of the pan plus sample, multiplied by the proportion of the total DWS. Total lipids were calculated by multiplying the lipid content per dry weight of the subsample by the total dry weight of the whole branch.

2.3. Symbiont Densities and Chlorophyll a Pigments. To determine the influence of symbiont densities and the photosynthetic pigment chlorophyll $a$ on coral lipids and reproduction, frozen branches were stripped of tissue using an air gun and the resultant slurry was macerated with a tissue homogenizer for $20 \mathrm{~s}$. The homogenate volume was recorded, and a $9 \mathrm{~mL}$ aliquot was drawn off and preserved with $1 \mathrm{~mL}$ of formalin $\left(32 \% \mathrm{w} \cdot \mathrm{w}^{-1}\right)$. Symbiont counts were made on eight independent drops $\left(0.0001 \mathrm{~mm}^{3}\right)$ from each sample using a New Improved Nuebauer haemocytometer under a compound light microscope. Symbiont numbers were standardized to coral tissue surface area using the $3 \mathrm{D}$ digital image analysis method described in Jones et al. [37].

A separate $10 \mathrm{ml}$ aliquot was drawn from the remaining tissue homogenate and the algal pellet was separated from the host tissue by centrifugation ( $3000 \mathrm{~g}$ for 5 minutes) at $4^{\circ} \mathrm{C}$. Chlorophyll was extracted overnight from the algal pellet using $100 \%$ methanol at $4^{\circ} \mathrm{C}$. The first 10 samples were extracted three times to determine the extraction efficiency. Absorbance at $668 \mathrm{~nm}$ and $635 \mathrm{~nm}$ was measured with a spectrophotometer (Hitachi U-3200). Total branch chlorophyll $a$ was calculated from the equation of Jeffrey and Haxo [40] after adjustment for extraction efficiency and standardized to algal cells. 
2.4. Reproduction. Branches that had been stored in $10 \%$ formaldehyde and seawater were decalcified in $15 \mathrm{~mL}$ Falcon tubes using 6\% hydrochloric acid and 2\% formaldehyde in reverse osmosis ( $\mathrm{RO}$ ) purified water. The decalcifying solution was changed twice over three days until no skeletal material remained. Samples were then washed in RO water and stored in $15 \mathrm{~mL}$ Falcon tubes in 5\% formaldehyde and RO water.

Six polyps were haphazardly selected from each decalcified coral branch and removed from the branch under a stereomicroscope [41]. Individual polyps were then dissected under a light microscope with a calibrated eyepiece micrometer $(0.25 \mathrm{~mm},[42,43])$ to expose the mesenteries. Maximum "length" and "width" measurements were taken for each egg $[41,44]$. The size was calculated as the width multiplied by the length. The total number and the size of each egg and sperm bundle (hereafter referred to as eggs) were recorded for each of the six polyps.

\section{Statistical Analysis}

3.1. Lipids, Symbiont Densities and Chlorophyll a Content. To investigate the effects of symbiont type and sampling occasion on lipid stores and symbiont densities before the bleaching, data were analysed with a multivariate repeated measure ANOVA using symbiont type (fixed, two levels) as the predictor variable and sampling occasion (random, two levels) as the repeated measure in the analysis.

To investigate the effects of symbiont type on the chlorophyll $a$ content in A. millepora colonies before the bleaching, data were analysed with univariate ANOVA using symbiont type (fixed, two levels) as the predictor variable in the analysis. Postbleaching samples were not included in these analyses because the adoption of multiple types and the dynamic nature of the symbiont community prevented a robust statistical analysis given the small sample sizes involved.

The symbiont changes following the bleaching prevented a direct comparison of lipids, symbiont densities and chlorophyll $a$ content of colonies with respect to symbiont type. To investigate the effects of the bleaching on lipid stores, chlorophyll $a$ content and symbiont densities were analysed with a repeated measure ANOVA using colony bleaching condition (fixed, two levels) as the predictor variable and sampling occasion (random, four levels) as the repeated measure in the analysis.

3.2. Reproduction. To investigate the effects of symbiont genotype on the reproductive output of $A$. millepora colonies before the bleaching event, data for prespawning lipids, egg number, and egg size were analysed with a single factor multivariate ANOVA using symbiont type (two levels) as the fixed predictor variable in the model. Model II regression analysis was used to investigate significant relationships between prespawning lipids, lipid allocation (prespawning lipids minus postspawning lipids), colony size, and egg number and egg size.

The symbiont changes following the bleaching prevented a direct comparison of colony reproductive output with respect to symbiont type. To investigate the effects of the bleaching event on the reproductive output of $A$. millepora colonies, data for prespawning lipids, egg number and egg size were analysed with a multivariate repeated measures ANOVA using bleaching condition (two levels) as the fixed predictor variable and year (random, two levels, before and after the bleaching event) as the repeated measure in the model.

In all analyses described above, scatterplots of the unstandardized residuals and standardized predicted values were used to verify the normality of the data and Levene's tests were used to verify the homogeneity of variances. Wherever significant interactions between predictor variables were found, simple, pairwise comparisons were performed using Sidak's adjustment for multiple comparisons [45]. In all repeated measures analyses if sphericity of the data could not be assumed, significance values were adjusted using the Greenhouse-Geisser epsilon. All statistical analyses in the study were performed using SPSS version 17.0.

\section{Results}

4.1. Symbiont Identification. The onset of the bleaching occurred just prior to January 2006 when the A. millepora colonies in the study had begun to appear pale or "fluorescent". The bleaching peaked in February 2006 when water temperatures remained at $>29^{\circ} \mathrm{C}$ for over two weeks [11-year mean summer temperature (December-February) $=27.0 \pm$ $0.5^{\circ} \mathrm{C}$, mean \pm S.D; R. Berkelmans, unpublished data]. As a result of heat stress, 10 of the original 12 colonies with C2 symbionts bleached white due to loss of symbionts. The remaining two original C2 colonies were unbleached because they had changed to host predominantly type D symbionts between November 2005 and January 2006. All 12 of the original type D colonies and these two colonies retained their normal prebleaching colouration. All 24 colonies survived the bleaching and had returned to their normal prebleaching colouration by May 2006. Of the 10 prebleaching (January 2006) type $C 2$ colonies, two changed to type $D$ upon recovery, one colony recovered with a mix of $\mathrm{C} 2$ and $\mathrm{D}$, one colony with a mix of $\mathrm{D}$ and $\mathrm{C} 1$, three with a mix of $\mathrm{C} 2$ and $\mathrm{C} 1$, and three colonies changed to a monomorphic $\mathrm{C} 1$ symbiont community. Ten of the original $12 \mathrm{D}$ colonies retained their $\mathrm{D}$ symbionts, one colony changed to $\mathrm{C} 1$ and one colony gained C1 as "background" symbionts (Figure 2). The two colonies that changed from C2 to D before the bleaching retained their new D symbiont types throughout and after the bleaching event. These symbiont changes provided an opportunity to investigate the lipids and reproduction of specific colonies during their recovery but prevented a direct comparison of the differential effects of bleaching on the lipids and reproduction with respect to symbiont type (D versus $\mathrm{C} 2$ colonies).

\subsection{Prebleaching}

4.2.1. Lipids. Before the bleaching event, lipid content in $A$. millepora colonies varied significantly with the predominant symbiont genotype $(P<.05)$. The mean annual lipid content 
(a) January 2006

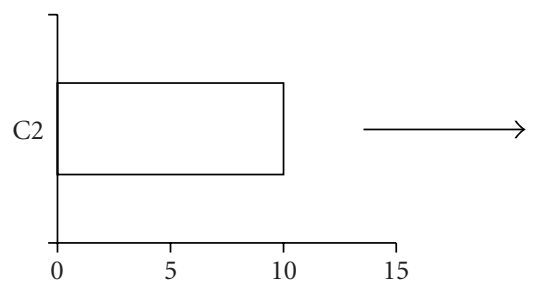

(d) January 2006

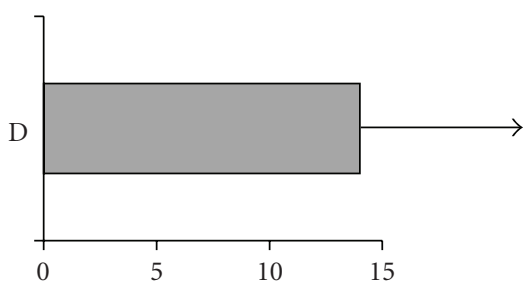

(b) May 2006

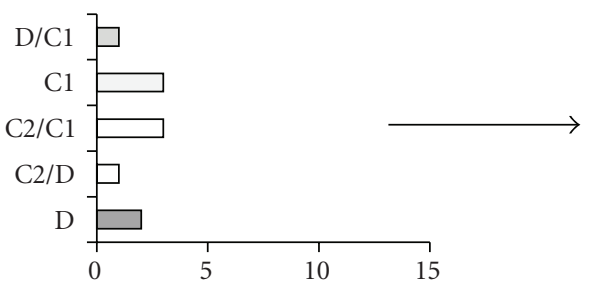

(e) May 2006

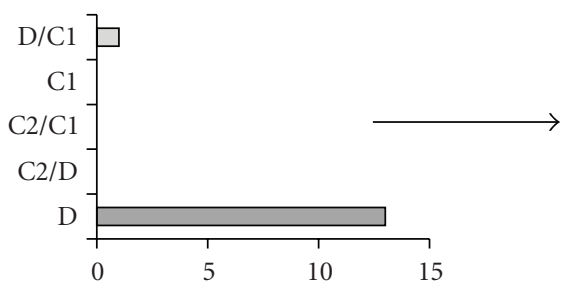

(c) August 2006

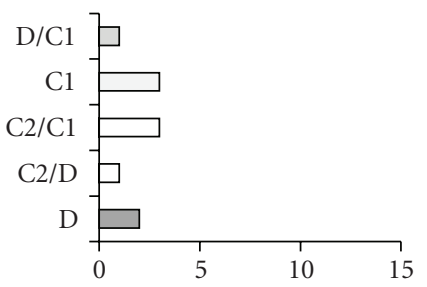

(f) August 2006

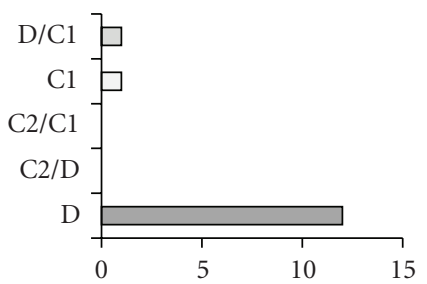

FIGURE 2: Symbiont community changes in colonies of Acropora millepora following a bleaching event in February 2006. (a)-(c). Two of the original $12 \mathrm{C} 2$ colonies changed to type D symbionts, one colony recovered with $\mathrm{C} 2$ and $\mathrm{D}$, one colony changed to D and $\mathrm{C} 1$, three colonies changed to $\mathrm{C} 1$, and three colonies recovered with both $\mathrm{C} 2$ and $\mathrm{C} 1$ symbionts. (d)-(f). Ten of the original D colonies retained their $\mathrm{D}$ symbionts, one colony changed to $\mathrm{C} 1$, and one colony gained $\mathrm{C} 1$ symbionts.

of type $\mathrm{D}$ colonies was $2.5 \pm 0.3 \mathrm{mg} \mathrm{cm}^{-2}$ (mean \pm S.E.), $26 \%$ lower than that of type C2 colonies which was $3.4 \pm$ $0.3 \mathrm{mg} \mathrm{cm}^{-2}$ (mean \pm S.E., Figure 3(a), Table $1, P<.05$ ).

4.2.2. Symbiont Densities and Chlorophyll a Pigments. Chlorophyll $a$ content in A. millepora colonies also varied significantly with symbiont genotype before the bleaching event (based on data from July 2005, Figure 3(b), Table 2). The mean chlorophyll $a$ content of symbionts for type $\mathrm{D}$ colonies was $28.5 \pm 1.9 \times 10^{-6} \mu$ c cell $^{-1}, 21 \%$ lower than for type C2 colonies which had $35.9 \pm 1.9 \times 10^{-6} \mu$ g cell $^{-1}$ (mean \pm S.E., $P<.05)$.

Symbiont densities of A. millepora colonies were not significantly different between symbiont genotypes before the bleaching (Figure 3(c)). However, type D colonies had $71 \%$ higher densities in the winter following the bleaching $\left(3.1 \pm 0.3 \times 10^{6}\right.$ cells $\mathrm{cm}^{-2}$, mean \pm S.E. $)$ compared to summer densities $\left(1.8 \pm 0.2 \times 10^{6}\right.$ cells $\mathrm{cm}^{-2}$, mean \pm S.E., $P<.05)$.

4.2.3. Reproduction. Lipids and egg sizes varied significantly with predominant symbiont genotype before the bleaching (Table 3). In the lead up to the annual mass spawning in 2005, lipids reached their highest levels just before spawning in November; an increase of $37 \%$ compared to July $(P<$ $.05)$, and decreased by $38 \%$ following spawning $(P<$ $.05)$. Prespawning lipids were positively correlated with egg numbers $\left(r^{2}=0.01, P<.001\right)$ and negatively correlated with egg sizes $\left(r^{2}=0.05, P=.017\right.$, Figure 4$)$. There was no significant correlation between lipid allocation to spawning (pre- minus postspawning lipids) and eggs (number or size).

Type D colonies had $3.1 \pm 0.4 \mathrm{mg} \mathrm{cm}^{-2}$ (mean \pm S.E.) stored lipids before the annual spawning, 34\% less than
C2 colonies which had $4.6 \pm 0.8 \mathrm{mg} \mathrm{cm}^{-2}$ (mean \pm S.E., $P<.05$, Figure 5(a)). The eggs in type D colonies measured $4.2 \pm 0.5 \mathrm{~mm}^{2}$ mean \pm S.E., $28 \%$ smaller than the eggs of $\mathrm{C} 2$ colonies which measured $5.9 \pm 0.6 \mathrm{~mm}^{2}$ (mean \pm S.E., $P<.05$, Figure 5(b)). All the polyps dissected from C2 colonies contained egg bundles. Two of the type D colonies contained no eggs in any of the six haphazardly selected polyps. There was no significant effect of symbiont genotype on egg numbers (Figure 5c).

\subsection{Postbleaching}

4.3.1. Lipids. The bleaching event in early 2006 had a profound effect on lipid levels in A. millepora (Figure 3(a), Tables 4 and 5). The storage lipids in the tagged colonies followed a similar pattern to symbiont densities, and chlorophyll $a$ content, declining to $~ 59 \%$ of January levels by May 2006, three months after the peak of the bleaching (Figures 3(b)$3(\mathrm{c})$ ). Lipids remained 21\% lower than prebleaching levels (based on the mean annual lipid content) in August 2006, six months after the peak of bleaching $(P<.05)$.

Although the lipids of all colonies (irrespective of prebleaching symbiont type or conditions) were affected by the temperature stress, colonies that originally had C2 symbionts that bleached white were affected more severely than those with type $\mathrm{D}$ symbionts that appeared unbleached $(P<.005)$. The 10 bleached C2 colonies lost $67 \%$ of their lipids between February and May $2006(P<.05)$, whereas the 14 unbleached type D colonies lost only $43 \%$ of their lipids which for those months was not significantly different to their prebleaching levels. The time-frame for this decline in lipid content is consistent with that described by Anthony et al. [28] for acroporid corals two months after bleaching. Recovering 


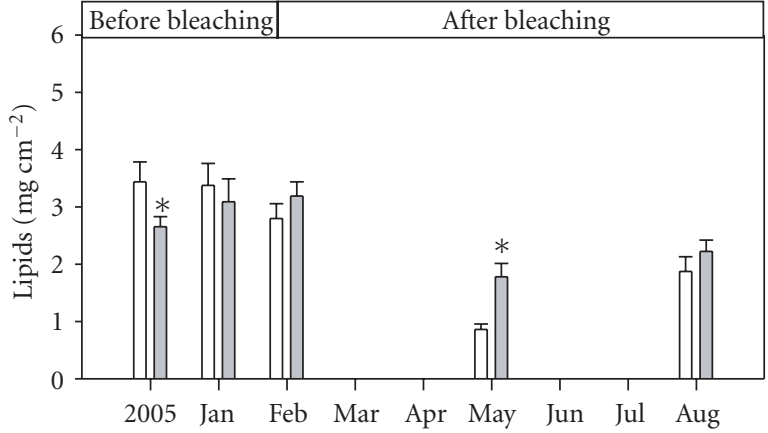

(a)

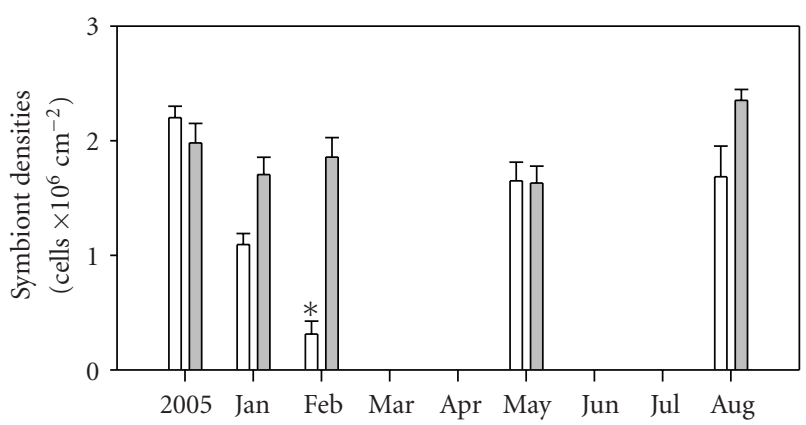

(b)

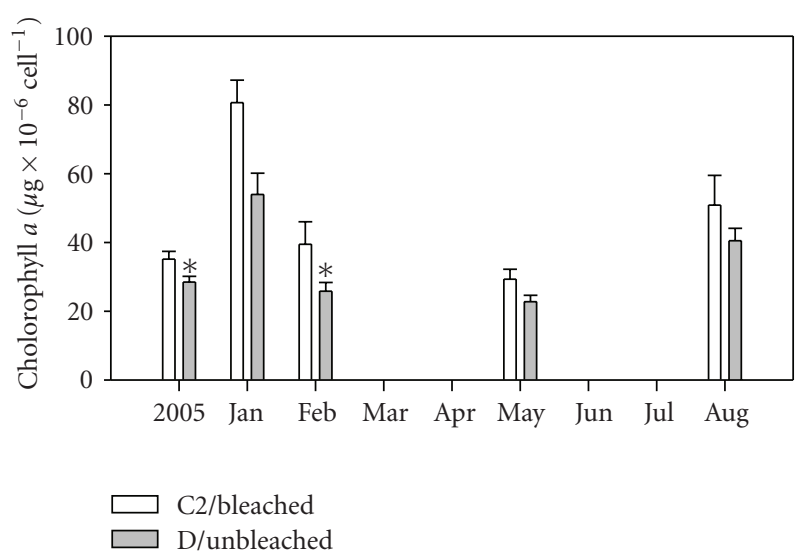

(c)

Figure 3: (a) Lipids, (b) chlorophyll $a$ content, and (c) symbiont densities of Acropora millepora in the year before and after a bleaching event that occurred in February 2006. White bars represent colonies that had predominantly C2 symbionts before the bleaching and bleached white and grey bars represent colonies with predominantly D symbionts that did not bleach. Whisker bars above the bars represent the standard error of the mean. * represent significant differences.

bleached colonies (which now had a mixture of C1, D, and C2 symbionts) had regained $82 \%$ of their lipids between May and August, six months after the event $(P<.05)$.

4.3.2. Symbiont Densities and Chlorophyll a Pigments. Colonies that had type $\mathrm{C} 2$ symbionts before the bleaching lost $72 \%$ of their symbionts between January and February $2006(P<.05$, Figure $3(\mathrm{~b}))$. In contrast, symbiont densities in unbleached type D colonies were not significantly affected. Between February and May 2006, bleached, original type C2 colonies (which now had mostly C1 and D symbionts) regained $82 \%$ of their prebleaching symbiont densities $(P<$ $.001)$.

Symbiont chlorophyll $a$ concentrations in all colonies were 53\% lower in February compared to the levels in January but had recovered by May and August $2006(P<$ .05 , Figure $3(\mathrm{c}))$. There were no significant differences in the symbiont chlorophyll $a$ content of colonies with respect to their new symbiont types or their condition during the bleaching event.

4.3.3. Reproduction. Temperature stress affected the prespawning lipids and egg size of $A$. millepora colonies irrespective of their condition (bleached or unbleached, $P<.05$, Figures 5(a)-5(c), Table 6). In November 2006, the mean prespawning lipids of the colonies in the study was $1.51 \pm$ $0.19 \mathrm{mg} \mathrm{cm}^{-2}$ (mean \pm S.E.), $62 \%$ lower compared to levels for the same period in $2005(P<.05$, Figure 5(a)). In spite of the significant difference between the sizes of eggs in $\mathrm{C} 2$ and $\mathrm{D}$ colonies before the bleaching $(P<.05$, Figure 5(b)) there were no differences with respect to symbiont type (C2 or D) or colony condition in egg sizes after the bleaching. The mean number of eggs in colonies irrespective of their prebleaching symbiont type was $4.1 \pm 0.3$ eggs polyp ${ }^{-1}$ (mean \pm S.E.), $41 \%$ less than numbers in $2005(P<.05$, Figure $5(\mathrm{c}))$.

\section{Discussion}

Our results show that climate change may diminish the energy stores and fecundity of reef corals in two separate and independent processes. First, the stored lipids will be diminished and the egg sizes decreased in colonies that host predominantly type $\mathrm{D}$ symbionts under normal conditions. Second, the lipids and egg numbers will be depleted by the very stress event that caused symbiont shuffling to more thermally tolerant types in the first place. While the effects may in part be due to changed symbiont types, the decrease in lipids and egg numbers post-bleaching was much greater than could be accounted for by symbiont type based on prebleaching data. Under normal conditions, A. millepora that host thermally tolerant type D symbionts had $26 \%$ lower lipid stores and $28 \%$ smaller eggs compared to C2 colonies. A severe bleaching event in 2006 [46] resulted in a significant Symbiodinium community shift from type C2 to types D and C1 symbionts in the A. millepora colonies at the study site. The shift may have resulted in at least temporarily greater resistance to heat stress [3], but the tradeoff was reduced energy stores leading to lower gamete numbers for all colonies, irrespective of either symbiont genotype before the bleaching or condition during the bleaching. While bleached colonies fared much worse than unbleached colonies in their post-bleaching capacity to produce and store lipids and ultimately in the numbers of gametes they produced, even unbleached colonies were affected by the heat stress with an estimated overall reduction of $55 \%$ in prespawning lipids and $29 \%$ in egg numbers compared to the previous season. 


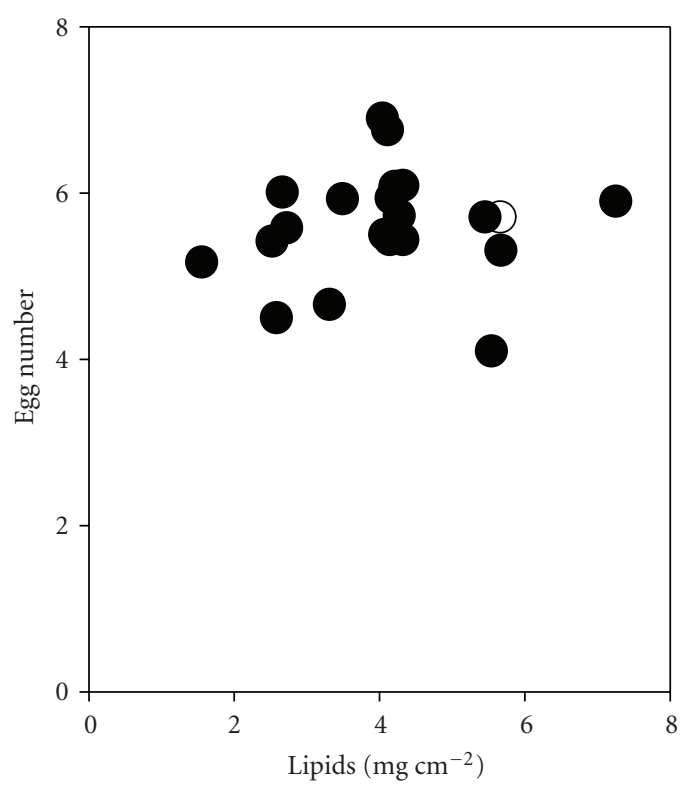

(a)

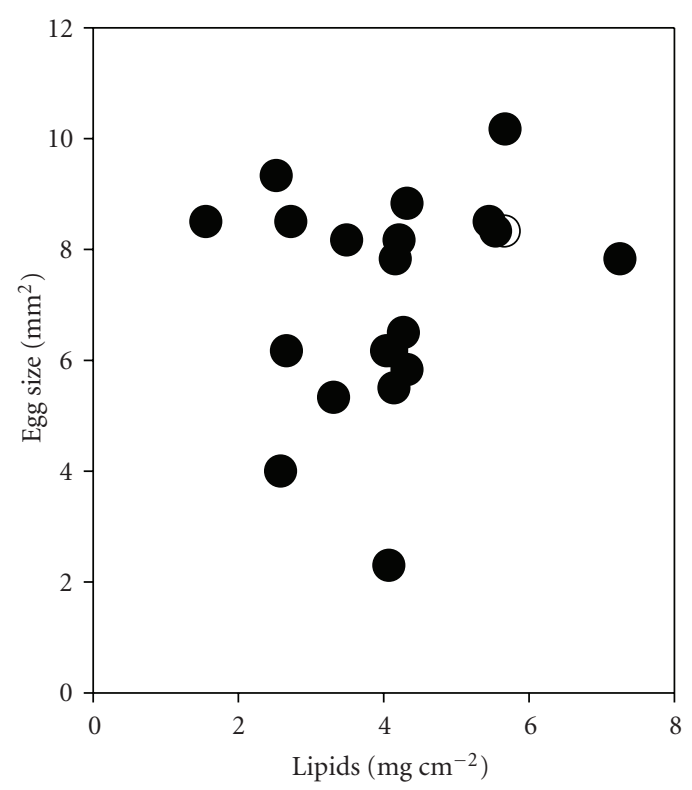

(b)

FIGURE 4: Scatterplots showing the significant correlations between prespawning lipids and (a) egg numbers $(r 2=0.01, P<.001)$ and (b) egg sizes $(r 2=0.05, P=.017)$ in Acropora millepora colonies in the year before a bleaching event.

TABLE 1: The results of a multivariate repeated measure ANOVA showing the significant between-subject effect of type (C2 or D) on lipid stores of Acropora millepora colonies before a bleaching. *indicate significant results.

\begin{tabular}{lcccccc}
\hline & Measure & S.S. & df & Mean square & F & Sig. \\
\hline \multirow{2}{*}{ Intercept } & Lipids & 428.53 & 1 & 428.53 & 256.6 & 0.000 \\
& Symbiont densities & 275.91 & 1 & 275.91 & 465.3 & 0.000 \\
\multirow{2}{*}{ Type } & Lipids & 9.68 & 1 & 9.68 & $0.025^{*}$ \\
& Symbiont densities & 0.33 & 1 & 0.33 & 0.4 \\
\multirow{2}{*}{ Error } & Lipids & 36.74 & 22 & 1.67 & \\
& Symbiont densities & 13.05 & 22 & & \\
\hline
\end{tabular}

Coral bleaching results in the loss of a readily available source of photosynthetically fixed carbon to the coral host. Until it recovers its symbiont community, the coral has to survive temporarily on its stored energy reserves. By far the most important source of this energy is lipids which can account for $10-40 \%$ of dry tissue weight [4749] and can provide $\sim 78-90 \%$ metabolic energy requirements of the coral $[14,50,51]$. In zooxanthellate corals without heterotrophic-autotrophic plasticity stored lipids are depleted following bleaching, without being replenished as they are gradually used for cellular repair and metabolism [52]. The loss of autotrophy as a direct result of symbiont expulsion clearly contributed to the depletion of lipid stores in bleached type C2 colonies. Two phenomena are remarkable here. The first is that stored lipids of bleached C2 colonies rapidly recovered to levels comparable with those of their unbleached counterparts in spite of recovering with the less photosynthetically efficient type D and C1 symbionts [15, 17-19]. The second is that unbleached type
D colonies, which did not lose their symbionts, still had drastically reduced lipids compared to prebleaching levels for up to 9 months following the bleaching. This is supported by Grottoli et al. [53] who found that even unbleached Porites compressa and Montipora verrucosa colonies had $\sim 16 \%$ and $24 \%$ less stored lipids, respectively, following a bleaching event in Hawaii in 1996, compared to the same season in previous nonbleaching years. Clearly there are factors at play other than the loss of symbionts. However, even more importantly, the temporary loss or interruption of their lipid production and storage capacity can place corals at risk of mortality after a thermal stress event regardless of their symbiont community or bleaching status $[27,28]$.

This study is one of several to demonstrate that factors other than the temporary loss of the symbionts are key determinants of the way that reef corals respond to temperature stress. Abrego et al. [54] demonstrated that light utilization efficiency, photosynthetic reaction centre integrity, and light prehistory may all play a part in the physiological response of 
TABLE 2: The results of a univariate ANOVA showing the significant effect of predominant symbiont type (C2 or D) on the chlorophyll $a$ content of Acropora millepora colonies in winter (July 2005) before a bleaching. The corrected model shows the variation in the dependent variable by other effects (other than the intercept) after correction for the mean. *indicate significant results.

\begin{tabular}{|c|c|c|c|c|c|}
\hline & S.S. & $\mathrm{df}$ & Mean Square & $\mathrm{F}$ & Sig. \\
\hline Corrected Model & $331.00^{\mathrm{a}}$ & 1 & 331.00 & 7.4 & 0.013 \\
\hline Intercept & 24837.84 & 1 & 24837.84 & 551.9 & 0.000 \\
\hline Type & 331.00 & 1 & 331.00 & 7.4 & $0.013^{*}$ \\
\hline Error & 990.02 & 22 & 45.00 & & \\
\hline Total & 26158.86 & 24 & & & \\
\hline Corrected Total & 1321.02 & 23 & & & \\
\hline
\end{tabular}

${ }^{(a)} \mathrm{R}$ Squared $=0.251$ (Adjusted R Squared $=0.217$ ).

TABle 3: ANOVA table showing the significant effect of symbiont Type (C2, D) on pre- and postspawning lipids and egg size (mm²) in Acropora millepora colonies before the bleaching. The corrected model shows the variation in the dependent variable by other effects (other than the intercept) after correction for the mean. *indicate significant results.

\begin{tabular}{|c|c|c|c|c|c|c|}
\hline & Measure & S.S. & df & Mean square & $\mathrm{F}$ & Sig. \\
\hline \multirow{3}{*}{ Corrected model } & Lipids & $14.25^{(\mathrm{a})}$ & 1 & 14.25 & 8.4 & 0.009 \\
\hline & Egg size & $16.18^{(\mathrm{b})}$ & 1 & 16.18 & 6.8 & 0.017 \\
\hline & Egg number & $21.08^{(\mathrm{c})}$ & 1 & 21.08 & 3.1 & 0.095 \\
\hline \multirow{3}{*}{ Intercept } & Lipids & 334.63 & 1 & 334.63 & 197.1 & 0.000 \\
\hline & Egg size & 594.46 & 1 & 594.46 & 249.2 & 0.000 \\
\hline & Egg number & 969.94 & 1 & 969.94 & 140.3 & 0.000 \\
\hline \multirow{3}{*}{ Type } & Lipids & 14.25 & 1 & 14.25 & 8.4 & $0.009^{*}$ \\
\hline & Egg size & 16.18 & 1 & 16.18 & 6.8 & $0.017^{*}$ \\
\hline & Egg number & 21.08 & 1 & 21.08 & 3.1 & 0.095 \\
\hline \multirow{3}{*}{ Error } & Lipids & 35.65 & 21 & 1.70 & & \\
\hline & Egg size & 50.09 & 21 & 2.39 & & \\
\hline & Egg number & 145.13 & 21 & 6.91 & & \\
\hline \multirow{3}{*}{ Total } & Lipids & 391.20 & 23 & & & \\
\hline & Egg size & 670.43 & 23 & & & \\
\hline & Egg number & 1150.48 & 23 & & & \\
\hline \multirow{3}{*}{ Corrected total } & Lipids & 49.90 & 22 & & & \\
\hline & Egg size & 66.27 & 22 & & & \\
\hline & Egg number & 166.21 & 22 & & & \\
\hline
\end{tabular}

${ }^{(a)} \mathrm{R}$ Squared $=0.286$ (Adjusted $\mathrm{R}$ Squared $=0.252$ ).

(b) $\mathrm{R}$ Squared $=0.244$ (Adjusted R Squared $=0.208)$.

${ }^{(c)} \mathrm{R}$ Squared $=0.127$ (Adjusted R Squared $=0.085$ ).

TABLE 4: Results of repeated measures multivariate ANOVA showing the significant effect of sampling occasion (Jan, Feb, May, and Aug) on symbiont chlorophyll $a$ content and lipids and the significant interaction between sampling occasion and bleaching condition on the symbiont densities of Acropora millepora colonies following a bleaching event in February 2006. *indicate significant results.

\begin{tabular}{|c|c|c|c|c|c|c|}
\hline & Measure & S.S & $\mathrm{df}$ & Mean square & $\mathrm{F}$ & Sig. \\
\hline \multirow{3}{*}{ Sampling occasion } & Symbiont densities & 6.62 & 3 & 2.21 & 5.2 & $0.004^{*}$ \\
\hline & Chlorophyll $a$ & 14876.64 & 3 & 4958.88 & 11.5 & $0.000^{*}$ \\
\hline & Lipids & 46.74 & 2 & 22.94 & 14.3 & $0.000^{*}$ \\
\hline \multirow{3}{*}{ Sampling occasion* bleaching condition } & Symbiont densities & 7.85 & 3 & 2.62 & 6.2 & $0.001^{*}$ \\
\hline & Chlorophyll $a$ & 269.09 & 3 & 89.70 & 0.2 & 0.891 \\
\hline & Lipids & 3.50 & 2 & 1.72 & 1.1 & 0.356 \\
\hline \multirow{3}{*}{ Error (sampling occasion) } & Symbiont densities & 19.01 & 45 & 0.42 & & \\
\hline & Chlorophyll $a$ & 19477.60 & 45 & 432.84 & & \\
\hline & Lipids & 49.02 & 31 & 1.60 & & \\
\hline
\end{tabular}


TABLE 5: The between-subject effects of repeated-measures multivariate ANOVA showing the significant effect of condition (bleached or unbleached in February 2006) on the symbiont densities and algal chlorophyll a content of Acropora millepora colonies. * indicate significant results.

\begin{tabular}{|c|c|c|c|c|c|c|}
\hline & Measure & S.S. & $\mathrm{df}$ & Mean square & $\mathrm{F}$ & Sig. \\
\hline \multirow{3}{*}{ Intercept } & Symbiont densities & 206.51 & 1 & 206.51 & 229.4 & 0.000 \\
\hline & Chlorophyll $a$ & 122068.33 & 1 & 122068.33 & 507.1 & 0.000 \\
\hline & Lipids & 384.88 & 1 & 384.88 & 242.9 & 0.000 \\
\hline \multirow{3}{*}{ Bleaching condition } & Symbiont densities & 10.72 & 1 & 10.72 & 11.9 & $0.004^{*}$ \\
\hline & Chlorophyll $a$ & 1616.52 & 1 & 1616.52 & 6.7 & $0.020^{*}$ \\
\hline & Lipids & 2.82 & 1 & 2.82 & 1.8 & 0.202 \\
\hline \multirow{3}{*}{ Error } & Symbiont densities & 13.50 & 15 & 0.90 & & \\
\hline & Chlorophyll $a$ & 3610.80 & 15 & 240.72 & & \\
\hline & Lipids & 23.77 & 15 & 1.58 & & \\
\hline
\end{tabular}

TABLE 6: The results of a multivariate ANOVA showing the significant within-subject effect of year on the lipids and egg numbers in bleached C2 and unbleached D colonies of Acropora millepora before and after a bleaching event in February 2006. There was no significant effect of year on egg size and no significant interactions between bleaching condition and year. *indicate significant results.

\begin{tabular}{|c|c|c|c|c|c|c|}
\hline & Measure & S.S. & $\mathrm{df}$ & Mean Square & $\mathrm{F}$ & Sig. \\
\hline \multirow{3}{*}{ Year } & Lipids & 50.92 & 1 & 50.92 & 51.6 & $0.000^{*}$ \\
\hline & Egg size & 0.40 & 1 & 0.40 & 0.3 & 0.569 \\
\hline & Egg number & 58.73 & 1 & 58.73 & 14.8 & $0.001^{*}$ \\
\hline \multirow{3}{*}{ Year* bleaching condition } & Lipids & 3.02 & 1 & 3.02 & 3.1 & 0.098 \\
\hline & Egg size & 3.07 & 1 & 3.07 & 2.6 & 0.126 \\
\hline & Egg number & 8.06 & 1 & 8.06 & 2.0 & 0.172 \\
\hline \multirow{3}{*}{ Error (year) } & Lipids & 16.78 & 17 & 0.99 & & \\
\hline & Egg size & 20.14 & 17 & 1.18 & & \\
\hline & Egg number & 67.39 & 17 & 3.96 & & \\
\hline
\end{tabular}

different coral host-symbiont combinations. Warmer conditions during bleaching could increase host cell metabolism, placing a heavier metabolic demand on the stored energy reserves $[55,56]$. If the host's respiratory demands remained high throughout the bleaching (and possibly longer to help cope with the stress), stored lipids are used faster than they are synthesized by the recovering symbiont population. This could occur even in unbleached colonies [57, 58]. An alternative explanation is that in the colonies that retained their symbionts, the photosystems were still affected by the heat stress [59]. Reversible uncoupling of normal photosynthetic function, or photoinhibition, can potentially reduce carbon fixation under these conditions $[60,61]$. Diverting energy to heat protects the photosystems from excess excitation pressure. Downregulation of photosynthesis can also be achieved in corals by reducing the pigment content of algal cells which was observed in unbleached A. millepora colonies as reduced algal chlorophyll $a$ content during and immediately following the bleaching. A fourth explanation for the decrease in lipids in unbleached corals is that host factors play a part in lipid depletion through increased mucous production in response to stress [62]. It remains unclear exactly which of these factors or combination of factors contributed to the lower lipid stores of type D colonies in the year following the bleaching. What is clear is that in spite of increasing bleaching resistance, the thermal tolerance of the symbionts does not protect the coral from the detrimental but sublethal effects of the heat stress itself, especially in terms of post-bleaching lipid stores and gamete production.

Symbiont identity affects reproductive output of the holobiont in a different way to that of direct thermal stress. Under normal conditions, in the lead-up to the annual spawning event, the colonies with type D symbionts had less stored lipids available to contribute to egg production, leading to smaller eggs than type C2 colonies. For most reef-building corals the energy required for the development of planulae larvae is mainly derived from stored lipids: primarily triacylglycerides and esters $[48,63]$. A. millepora produce azooxanthellate larvae which acquire symbionts from the surrounding environment after settlement. Once acquired, the symbionts can provide $13-27 \%$ of the energetic requirements of the larvae via photosynthesis [64]. Until the symbiosis is established the larvae are dependent on the stored energy provided by the parent. These energy stores control two key factors of reproductive success, larval duration and settlement-competency periods [64]. Under nonstressful conditions $A$. millepora colonies with type $\mathrm{D}$ symbionts may be diverting smaller quantities of storage lipids to egg production than type C2 colonies because 


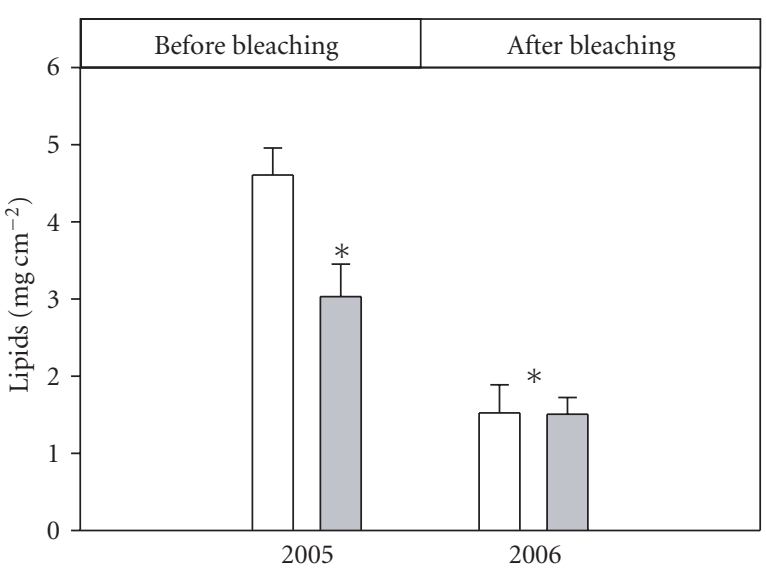

(a)

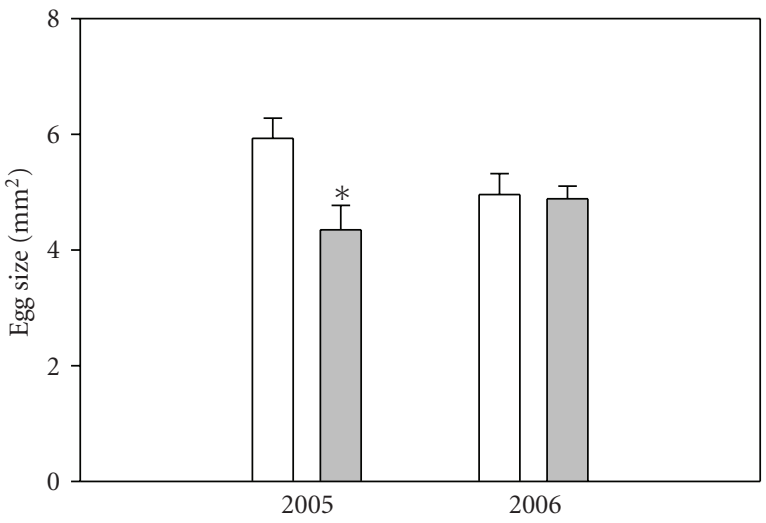

(b)

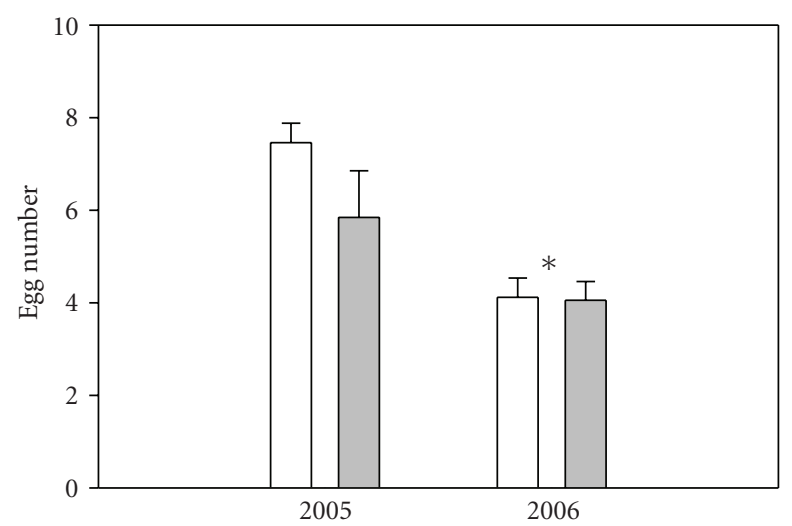

C2/bleached

D/unbleached

(c)

Figure 5: (a) Lipids, (b) egg size, and (c) egg numbers in colonies of Acropora millepora before and after a bleaching event that occurred in February 2006. White bars represent colonies with predominantly C2 symbionts before the bleaching that bleached white and grey bars represent colonies with predominantly D symbionts before the bleaching that were unbleached during the event. Whisker bars above the bars represent the standard error of the mean. * represent significant differences. smaller quantities are available to begin with. To accommodate for the reduced lipids available for egg generation, type $\mathrm{D}$ colonies appear to maintain egg numbers at a cost to egg size, maintaining the numerical odds of successful self-proliferation but at a cost to larval competency and subsequently, reducing the potential extent of geographic distribution [65]. During reproduction following a bleaching however, the opposite occurs. A. millepora colonies that have undergone temperature stress, regardless of their bleaching condition, produce fewer eggs but maintain egg sizes. Perhaps this ensures that adequate energy is available for the now limited number of larvae to survive longer and improves settlement-competency periods, reducing the numerical odds of self-proliferation but maintaining the range of geographic distribution.

This study has provided some insights into the synergistic effects and magnitude of symbiont genotype and thermal stress on the lipid stores and reproduction of Acropora corals. These two influences are likely to have significant implications for the bleaching resistance, mortality risk, and reproduction of corals that are capable of shuffling their symbionts as ocean temperatures warm with climate change. Not all corals can change their symbionts, and it has been argued that those that can, such as the Acropora, may be the exception rather than the rule $[66,67]$. However, it must be acknowledged that to date our understanding of symbiont shuffling is poor, especially in relation to which species (and populations within species) and the circumstances in which this process occurs. Novel molecular methods are revealing previously hidden symbiont diversity in many reef corals suggesting that under favorable conditions, the potential exists for different types to multiply and outcompete other types [68]. For corals that can shuffle, the results of this study suggest that the thermal tolerance of the predominant symbiont genotype can be detrimental to energetics and reproduction, and that this will be compounded by the longterm effects of severe heat stress even if they do survive. For those corals, acclimation by symbiont shuffling in response to warmer and more stressful conditions therefore may not represent as much of an ecological benefit as has previously been suggested [3]. However, (and more importantly) if sustained warmer conditions cause wholesale symbiont community change to more thermally tolerant types, then there will be compounding effects of symbiont identity and direct thermal stress on coral energy stores and reproduction.

\section{References}

[1] P. L. Jokiel and S. L. Coles, "Response of Hawaiian and other Indo-Pacific reef corals to elevated temperature," Coral Reefs, vol. 8, no. 4, pp. 155-162, 1990.

[2] G. A. Meehl et al., "Global climate projections," in Climate Change 2007: The Physical Science Basis, Contribution of: Working Group I to the Fourth Assessment Report of the Intergovernmental Panel on Climate Change, chapter 10, Cambridge University Press, New York, NY, USA, 2007.

[3] R. Berkelmans and M. J.H. Van Oppen, "The role of zooxanthellae in the thermal tolerance of corals: a 'nugget of hope' for coral reefs in an era of climate change," Proceedings of the Royal 
Society B: Biological Sciences, vol. 273, no. 1599, pp. 2305-2312, 2006.

[4] R. W. Buddemeier and D. G. Fautin, "Coral bleaching as an adaptive mechanism: a testable hypothesis," Bioscience, vol. 43, no. 5, p. 320, 1993.

[5] J. C. Mieog, M. J. H. Van Oppen, N. E. Cantin, W. T. Stam, and J. L. Olsen, "Real-time PCR reveals a high incidence of Symbiodinium clade D at low levels in four scleractinian corals across the Great Barrier Reef: implications for symbiont shuffling," Coral Reefs, vol. 26, no. 3, pp. 449-457, 2007.

[6] A. C. Baker, "Reef corals bleach to survive change," Nature, vol. 411, no. 6839, pp. 765-766, 2001.

[7] A. C. Baker, C. J. Starger, T. R. McClanahan, and P. W. Glynn, "Coral reefs: corals' adaptive response to climate change," Nature, vol. 430, no. 7001, p. 741, 2004.

[8] A. M. Jones, R. Berkelmans, M. J.H. Van Oppen, J. C. Mieog, and W. Sinclair, "A community change in the algal endosymbionts of a scleractinian coral following a natural bleaching event: field evidence of acclimatization," in Proceedings of the International Coral Reef Symposium, vol. 275, pp. 1359-1365, International Coral Reef Society, Fort Lauderdale, Fla, USA, June 2008.

[9] E. M. Sampayo, T. Ridgway, P. Bongaerts, and O. HoeghGuldberg, "Bleaching susceptibility and mortality of corals are determined by fine-scale differences in symbiont type," Proceedings of the National Academy of Sciences of the United States of America, vol. 105, no. 30, pp. 10444-10449, 2008.

[10] L. Muscatine, "The role of symbiotic algae in carbon and energy flux in reef corals," in Ecosystems of the World 25: Coral Reefs, B. Dubinsky, Ed., pp. 75-87, Elsevier, New York, NY, USA, 1990.

[11] L. F. Whitehead and A. E. Douglas, "Metabolite comparisons and the identity of nutrients translocated from symbiotic algae to an animal host," Journal of Experimental Biology, vol. 206, no. 18, pp. 3149-3157, 2003.

[12] P. S. Davies, "Effect of daylight variations on the energy budgets of shallow-water corals," Marine Biology, vol. 108, no. 1, pp. 137-144, 1991.

[13] V. Pearse and L. Muscatine, "Role of symbiotic algae (zooxanthellae) in coral calcification," Biological Bulletin, vol. 141, no. 2, pp. 350-363, 1971.

[14] P. J. Edmunds and P. S. Davies, "An energy budget for Porites porites (Scleractinia)," Marine Biology, vol. 92, pp. 339-347, 1986.

[15] N. E. Cantin, M. J. H. Van Oppen, B. L. Willis, J. C. Mieog, and A. P. Negri, "Juvenile corals can acquire more carbon from high-performance algal symbionts," Coral Reefs, vol. 28, no. 2, pp. 405-414, 2009.

[16] M. Stat, E. Morris, and R. D. Gates, "Functional diversity in coral-dinoflagellate symbiosis," Proceedings of the National Academy of Sciences of the United States of America, vol. 105, no. 27, pp. 9256-9261, 2008.

[17] A. F. Little, M. J. H. Van Oppen, and B. L. Willis, "Flexibility in algal endosymbioses shapes growth in reef corals," Science, vol. 304, no. 5676, pp. 1492-1494, 2004.

[18] J. C. Mieog, J. L. Olsen, R. Berkelmans, S. A. Bleuler-Martinez, B. L. Willis, and M. J. H. van Oppen, "The roles and interactions of symbiont, host and environment in defining coral fitness," PLoS ONE, vol. 4, no. 7, Article ID e6364, 2009.

[19] A. Jones and R. Berkelmans, "Potential costs of acclimatization to a warmer climate: growth of a reef coral with heat tolerant vs. sensitive symbiont types," PLoS ONE, vol. 5, no. 5, Article ID e10437, 2010.
[20] D. Tchernov, M. Y. Gorbunov, C. De Vargas et al., "Membrane lipids of symbiotic algae are diagnostic of sensitivity to thermal bleaching in corals," Proceedings of the National Academy of Sciences of the United States of America, vol. 101, no. 37, pp. 13531-13535, 2004.

[21] S. Hugly et al., "Enhanced thermal tolerance of photosynthesis and altered chloroplast ultrastructure in a mutant of Arabidopsis deficient in lipid desaturation," Plant Physiology, vol. 90, no. 3, pp. 1134-1142, 1989.

[22] A. Wahid, S. Gelani, M. Ashraf, and M. R. Foolad, "Heat tolerance in plants: an overview," Environmental and Experimental Botany, vol. 61, no. 3, pp. 199-223, 2007.

[23] M. Wakeford, T. J. Done, and C. R. Johnson, "Decadal trends in a coral community and evidence of changed disturbance regime," Coral Reefs, vol. 27, no. 1, pp. 1-13, 2008.

[24] O. Hoegh-Guldberg, M. Fine, W. Skirving, R. Johnstone, S. Dove, and A. Strong, "Coral bleaching following wintry weather," Limnology and Oceanography, vol. 50, no. 1, pp. 265$271,2005$.

[25] M. J. Devlin and J. Brodie, "Terrestrial discharge into the Great Barrier Reef Lagoon: nutrient behavior in coastal waters," Marine Pollution Bulletin, vol. 51, no. 1-4, pp. 9-22, 2005.

[26] S. Leuzinger, K. R. N. Anthony, and B. L. Willis, "Reproductive energy investment in corals: scaling with module size," Oecologia, vol. 136, no. 4, pp. 524-531, 2003.

[27] K. R. N. Anthony, S. R. Connolly, and O. Hoegh-Guldberg, "Bleaching, energetics, and coral mortality risk: effects of temperature, light, and sediment regime," Limnology and Oceanography, vol. 52, no. 2, pp. 716-726, 2007.

[28] K. R. N. Anthony, M. O. Hoogenboom, J. A. Maynard, A. G. Grottoli, and R. Middlebrook, "Energetics approach to predicting mortality risk from environmental stress: a case study of coral bleaching," Functional Ecology, vol. 23, no. 3, pp. 539-550, 2009.

[29] L. A. Henry and M. Hart, "Regeneration from injury and resource allocation in sponges and corals-a review," International Review of Hydrobiology, vol. 90, no. 2, pp. 125-158, 2005.

[30] E. M. Graham, A. H. Baird, and S. R. Connolly, "Survival dynamics of scleractinian coral larvae and implications for dispersal," Coral Reefs, vol. 27, no. 3, pp. 529-539, 2008.

[31] J. Tamelander, "Coral recruitment following a mass mortality event," Ambio, vol. 31, no. 7-8, pp. 551-557, 2002.

[32] R. van Woesik, "Impact of the floods on coral communities of the Keppel Islands, report to the Great Barrier Reef Marine Park Authority," Townsville, Australia, 1991.

[33] G. R. Almany, S. R. Connolly, D. D. Heath et al., "Connectivity, biodiversity conservation and the design of marine reserve networks for coral reefs," Coral Reefs, vol. 28, no. 2, pp. 339351, 2009.

[34] K. E. Fabricius, J. C. Mieog, P. L. Colin, D. Idip, and M. J. H. Van Oppen, "Identity and diversity of coral endosymbionts (zooxanthellae) from three Palauan reefs with contrasting bleaching, temperature and shading histories," Molecular Ecology, vol. 13, no. 8, pp. 2445-2458, 2004.

[35] J. W. Porter, W. K. Fitt, H. J. Spero, C. S. Rogers, and M. W. White, "Bleaching in reef corals: physiological and stable isotopic responses," Proceedings of the National Academy of Sciences of the United States of America, vol. 86, no. 23, pp. 9342-9346, 1989.

[36] B. E. Brown, C. A. Downs, R. P. Dunne, and S. W. Gibb, "Preliminary evidence for tissue retraction as a factor in photoprotection of corals incapable of xanthophyll cycling," 
Journal of Experimental Marine Biology and Ecology, vol. 277, no. 2, pp. 129-144, 2002.

[37] A. M. Jones, N. E. Cantin, R. Berkelmans, B. Sinclair, and A. P. Negri, "A 3D modeling method to calculate the surface areas of coral branches," Coral Reefs, vol. 27, no. 3, pp. 521-526, 2008.

[38] J. Folch, M. Lees, and G. H. Sloane Stanley, "A simple method for the isolation and purification of total lipides from animal tissues," The Journal of Biological Chemistry, vol. 226, no. 1, pp. 497-509, 1957.

[39] A. D. Harland, L. M. Fixter, P. S. Davies, and R. A. Anderson, "Effect of light on the total lipid content and storage lipids of the symbiotic sea anemone Anemonia viridis," Marine Biology, vol. 112, no. 2, pp. 253-258, 1992.

[40] S. W. Jeffrey and F. T. Haxo, "Photosynthetic pigments of symbiotic dinoflagellates (zooxanthellae) from corals and clams," Biological Bulletin, vol. 135, pp. 149-165, 1968.

[41] S. Ward, "The effect of damage on the growth, reproduction and storage of lipids in the scleractinian coral Pocillopora damicornis (Linnaeus)," Journal of Experimental Marine Biology and Ecology, vol. 187, no. 2, pp. 193-206, 1995.

[42] J. Oliver, Temporal and spatial variations in the growth of Acropora formosa (dana 1846) on a North Queensland fringing reef, Honours thesis, Marine Biology Department: James Cook University Townsville, Townsville, Australia, 1979.

[43] C. C. Wallace, "Reproduction, recruitment and fragmentation in nine sympatric species of the coral genus Acropora," Marine Biology, vol. 88, no. 3, pp. 217-233, 1985.

[44] S. Ward and P. Harrison, "Changes in gametogenesis and fecundity of acroporid corals that were exposed to elevated nitrogen and phosphorus during the ENCORE experiment," Journal of Experimental Marine Biology and Ecology, vol. 246, no. 2, pp. 179-221, 2000.

[45] S. L. Weinberg and S. K. Abramowitz, Data analysis for the Behavioral Sciences Using SPSS, Cambridge University Press, New York, NY, USA, 2002.

[46] A. M. Jones et al., "A community change in the symbionts of a scleractinian coral following a natural bleaching event: field evidence of acclimatization," Proceedings of the Royal Society B: Biological Sciences, vol. 275, pp. 1359-1365, 2008.

[47] A. D. Harland, J. C. Navarro, P. Spencer Davies, and L. M. Fixter, "Lipids of some Caribbean and Red Sea corals: total lipid, wax esters, triglycerides and fatty acids," Marine Biology, vol. 117, no. 1, pp. 113-117, 1993.

[48] J. S. Stimson, "Location, quantity and rate of change in quantity of lipids in tissue of Hawaiian hermatypic corals," Bulletin of Marine Science, vol. 41, no. 3, pp. 889-904, 1987.

[49] H. Yamashiro, H. Oku, H. Higa, I. Chinen, and K. Sakai, "Composition of lipids, fatty acids and sterols in Okinawan corals," Comparative Biochemistry and Physiology B, vol. 122, no. 4, pp. 397-407, 1999.

[50] P. S. Davies, "The role of zooxanthellae in the nutritional energy requirements of Pocillopora eydouxi," Coral Reefs, vol. 2, no. 4, pp. 181-186, 1984.

[51] L. Muscatine et al., "Fate of photosynthetic fixed carbon in light and shade-adapted colonies of the symbiotic coral Stylophora pistillata," Proceedings of the Royal Society B: Biological Sciences, vol. 222, pp. 181-202, 1984.

[52] K. R. N. Anthony and K. E. Fabricius, "Shifting roles of heterotrophy and autotrophy in coral energetics under varying turbidity," Journal of Experimental Marine Biology and Ecology, vol. 252, no. 2, pp. 221-253, 2000.

[53] A. G. Grottoli, L. J. Rodrigues, and C. Juarez, "Lipids and stable carbon isotopes in two species of Hawaiian corals, Porites compressa and Montipora verrucosa, following a bleaching event," Marine Biology, vol. 145, no. 3, pp. 621-631, 2004.

[54] D. Abrego, K. E. Ulstrup, B. L. Willis, and M. J.H. Van Oppen, "Species-specific interactions between algal endosymbionts and coral hosts define their bleaching response to heat and light stress," Proceedings of the Royal Society B: Biological Sciences, vol. 275, no. 1648, pp. 2273-2282, 2008.

[55] W. K. Fitt, F. K. McFarland, M. E. Warner, and G. C. Chilcoat, "Seasonal patterns of tissue biomass and densities of symbiotic dinoflagellates in reef corals and relation to coral bleaching," Limnology and Oceanography, vol. 45, no. 3, pp. 677-685, 2000.

[56] G. Muller-Parker, "Seasonal variation in light-shade adaptation of natural populations of the symbiotic sea anemone Aiptasia pulchella (Carlgren, 1943) in Hawaii," Journal of Experimental Marine Biology and Ecology, vol. 112, no. 2, pp. 165-183, 1987.

[57] M. E. Warner, W. K. Fitt, and G. W. Schmidt, "The effects of elevated temperature on the photosynthetic efficiency of zooxanthellae in hospite from four different species of reef coral: a novel approach," Plant, Cell and Environment, vol. 19, no. 3, pp. 291-299, 1996.

[58] S. Takahashi, T. Nakamura, M. Sakamizu, R. Van Woesik, and H. Yamasaki, "Repair machinery of symbiotic photosynthesis as the primary target of heat stress for reef-building corals," Plant and Cell Physiology, vol. 45, no. 2, pp. 251-255, 2004.

[59] R. J. Jones, O. Hoegh-Guldberg, A. W. D. Larkum, and U. Schreiber, "Temperature-induced bleaching of corals begins with impairment of the $\mathrm{CO}_{2}$ fixation mechanism in zooxanthellae," Plant, Cell and Environment, vol. 21, no. 12, pp. 1219 1230, 1998.

[60] R. Rowan, "Thermal adaptation in reef coral symbionts," Nature, vol. 430, no. 7001, p. 742, 2004.

[61] R. Hill and P. J. Ralph, "Photosystem II heterogeneity of in hospite zooxanthellae in scleractinian corals exposed to bleaching conditions," Photochemistry and Photobiology, vol. 82, no. 6, pp. 1577-1585, 2006.

[62] S. A. Wooldridge, "A new conceptual model for the enhanced release of mucus in symbiotic reef corals during 'bleaching' conditions," Marine Ecology Progress Series, vol. 396, pp. 145152, 2009.

[63] I. Arai, M. Kato, A. Heyward, Y. Ikeda, T. Iizuka, and T. Maruyama, "Lipid composition of positively buoyant eggs of reef building corals," Coral Reefs, vol. 12, no. 2, pp. 71-75, 1993.

[64] S. Harii, M. Yamamoto, and O. Hoegh-Guldberg, "The relative contribution of dinoflagellate photosynthesis and stored lipids to the survivorship of symbiotic larvae of the reef-building corals," Marine Biology, vol. 157, no. 6, pp. 1215-1224, 2010.

[65] R. H. Richmond, "Energetics, competency, and long-distance dispersal of planula larvae of the coral Pocillopora damicornis," Marine Biology, vol. 93, no. 4, pp. 527-533, 1987.

[66] A. C. Baker and A. M. Romanski, "Multiple symbiotic partnerships are common in scleractinian corals, but not in octocorals: comment on Goulet (2006)," Marine Ecology Progress Series, vol. 335, pp. 237-242, 2007.

[67] D. J. Thornhill, YU. Xiang, W. K. Fitt, and S. R. Santos, "Reef endemism, host specificity and temporal stability in populations of symbiotic dinoflagellates from two ecologically dominant Caribbean corals," PLoS ONE, vol. 4, no. 7, Article ID e6262, 2009.

[68] J. C. Mieog et al., "Enormous potential forshuffling of algal symbionts in reef corals," Coral Reefs. In press. 

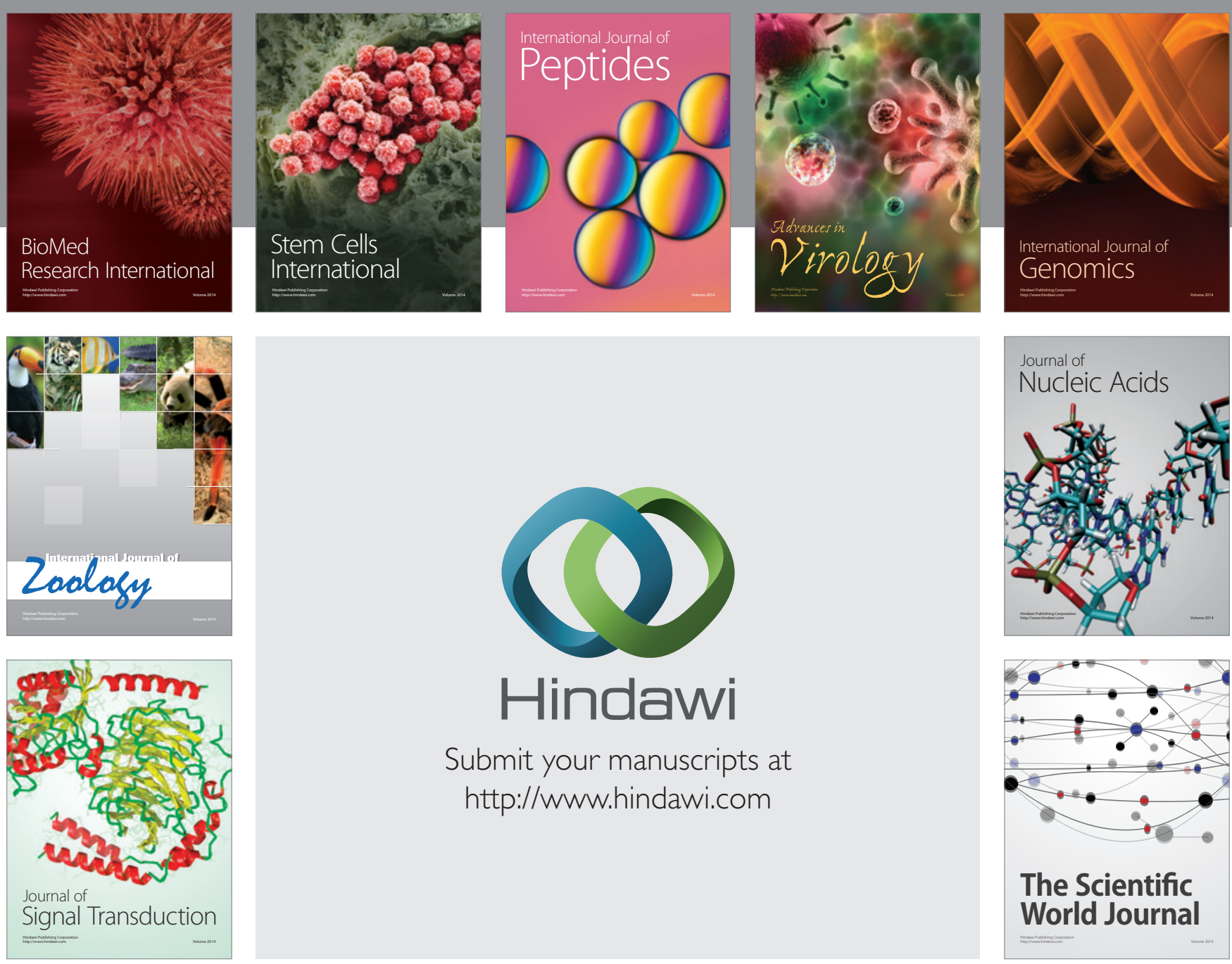

Submit your manuscripts at

http://www.hindawi.com
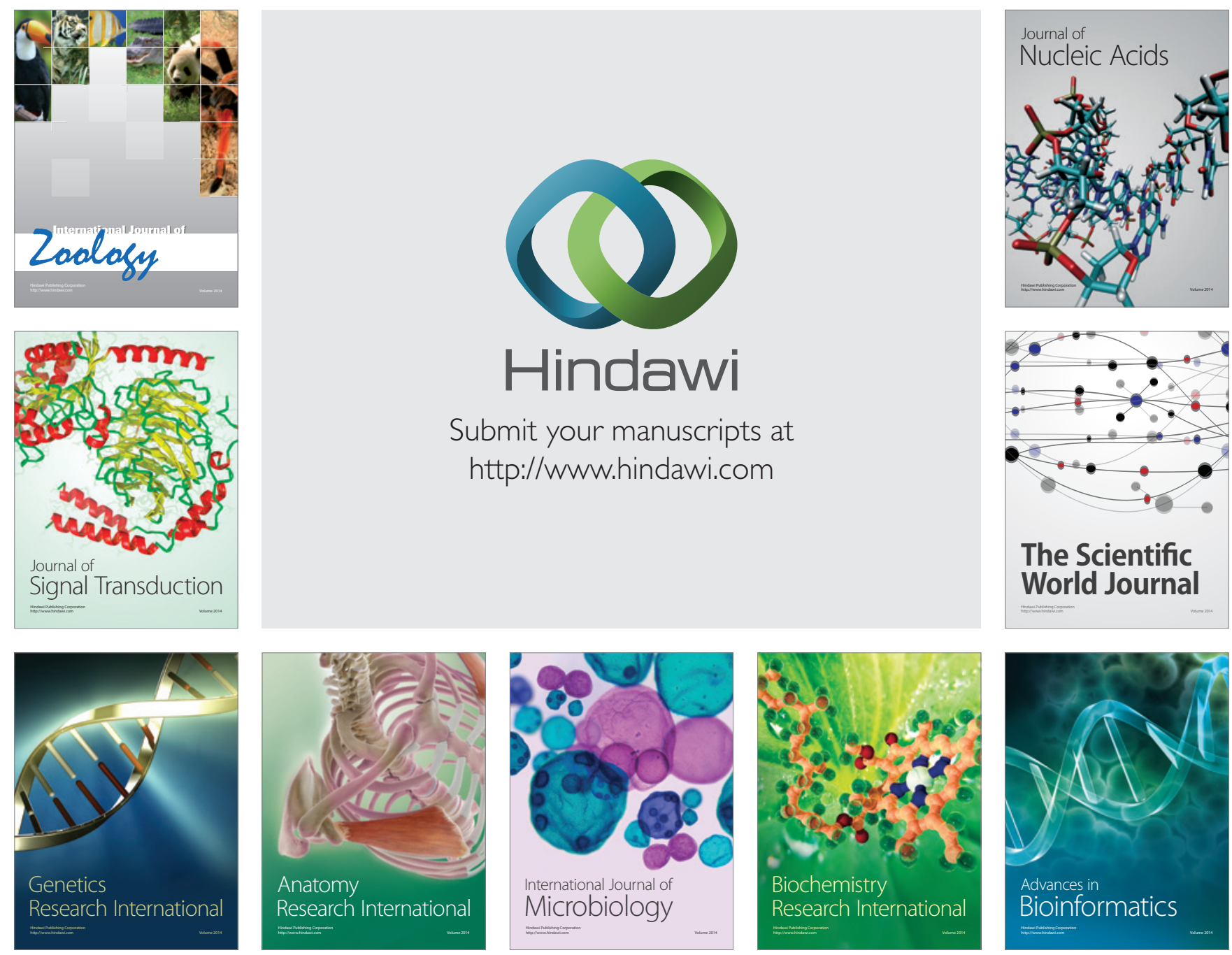

The Scientific World Journal
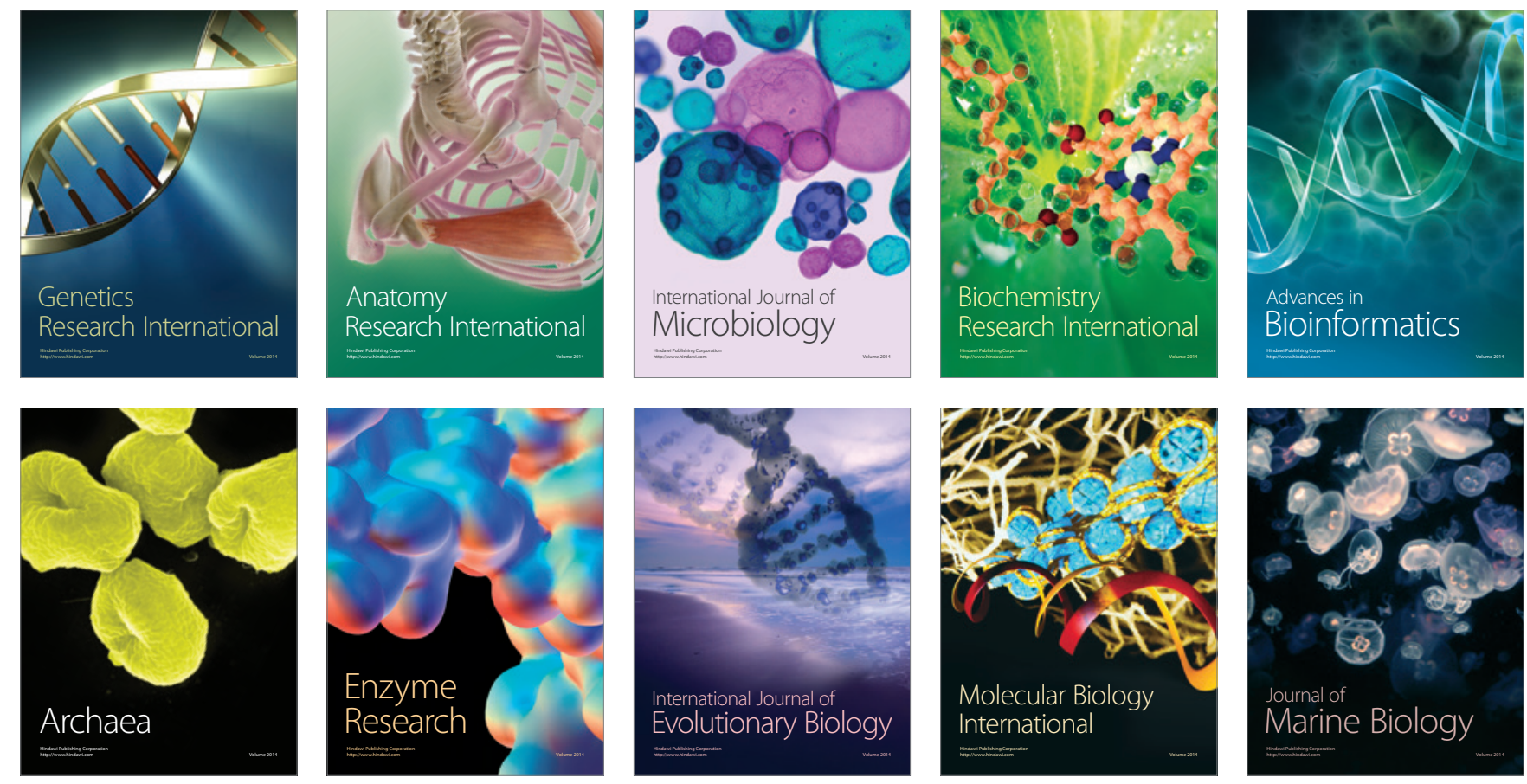